Case Report

\title{
Guiding Maxillary Left Central Incisor to Occlusion and Late Formation of a Supernumerary Tooth in the Upper Left Premolar Region
}

\author{
I. A. Alnaqbi $\mathbb{D}^{1,2}$ and A. O. Mageet $\mathbb{D}^{3,4}$ \\ ${ }^{1}$ Specialist Orthodontist, Ministry of Health \& Prevention, Sharjah, UAE \\ ${ }^{2}$ Orthodontic Resident, Hamdan Bin Mohammed College of Dental Medicine, MBRU, Dubai, UAE \\ ${ }^{3}$ Associate Professor of Orthodontics, Faculty of Dentistry, Ajman University and a Member of the Center of Medical and Bio-allied \\ Health Sciences, Ajman University, Ajman, UAE \\ ${ }^{4}$ Associate Prof. of Orthodontics, Hamdan Bin Mohammed College of Dental Medicine, MBRU, Dubai, UAE
}

Correspondence should be addressed to A. O. Mageet; amageet2000@yahoo.co.uk

Received 1 December 2020; Revised 8 January 2021; Accepted 15 January 2021; Published 30 January 2021

Academic Editor: Giuseppe Alessandro Scardina

Copyright (C) 2021 I. A. Alnaqbi and A. O. Mageet. This is an open access article distributed under the Creative Commons Attribution License, which permits unrestricted use, distribution, and reproduction in any medium, provided the original work is properly cited.

\begin{abstract}
Hyperdontia or supernumerary teeth are the erupted or impacted teeth, which develop in addition to the regular dental series and might cause many occlusal problems. This article sheds light on a case of impacted maxillary left central incisor (21) due to a mesiodens supernumerary tooth and a late development of another supernumerary tooth in the upper left premolar area at the end of orthodontic treatment. O.A. is an 11-year, eight-month-old male, African patient presented to the orthodontic clinic with a chief complaint "My upper front tooth did not erupt although the dentist attached a wire to pull it with the help of a neighbouring tooth." Clinically, he is medically fit and healthy, presented with class II division I malocclusion on skeletal II base; mild space discrepancy in the upper and lower dental arches; impacted 21; increased overjet; reduced overbite; localized bilateral posterior crossbite in relation to tooth number 16, 15, 25, and 26; and lower centreline shift to the left. Radiographically, lateral cephalometric radiograph confirms the skeletal relationship, whereas dental panoramic tomography (DPT) shows impacted 21 and the presence of all permanent teeth. The treatment plan consists of comprehensive orthodontic treatment using preadjusted edgewise metallic bracket, Roth prescription $0.022^{\prime \prime} \times 0.028^{\prime \prime}$ slot and an active transpalatal arch (TPA) with palatal arms. Retention regimen comprises of upper and lower bonded retainers from canine to canine and vacuumformed retainers (VFRs) for both dental arches.
\end{abstract}

\section{Introduction}

Supernumerary teeth could be found in many parts of the human body such as the ovary, nasal cavity, or hard palate; however, they are normally seen in the dental arches [1-3] with a higher incidence in the maxillary anterior region [4]. Development of these teeth can be in one or both dental arches, in a single or multiple forms, and their location could be of unilateral or bilateral [5]. The prevalence of supernumeraries in primary dentition was found to be $0.3-0.8 \%$ whereas it was $1.5-3.5 \%$ in permanent dentition $[6,7]$. Their presence varies among populations which is more in Asians $[3,8]$, and they are in males more than females [9]. The aetiology of supernumerary teeth is multifactorial [10], with different theories suggested dichotomy of tooth bud, hyperactivity of dental lamina [5, 6, 11], and genetic influences [12].

The frequency of supernumerary premolars was as high as $0.64 \%$ ( 7 in 1,100$)$ as seen in orthodontic population, and the age range of the patients when detecting the supernumerary premolars was between 11 and 16 years [13]. Several syndromes have been associated with supernumeraries such as Down's syndrome, cleidocranial dysplasia, cleft lip and palate, Gardner syndrome, Ellis-van Creveld syndrome, Zimmermann-Laband syndrome, or Noonan syndrome 


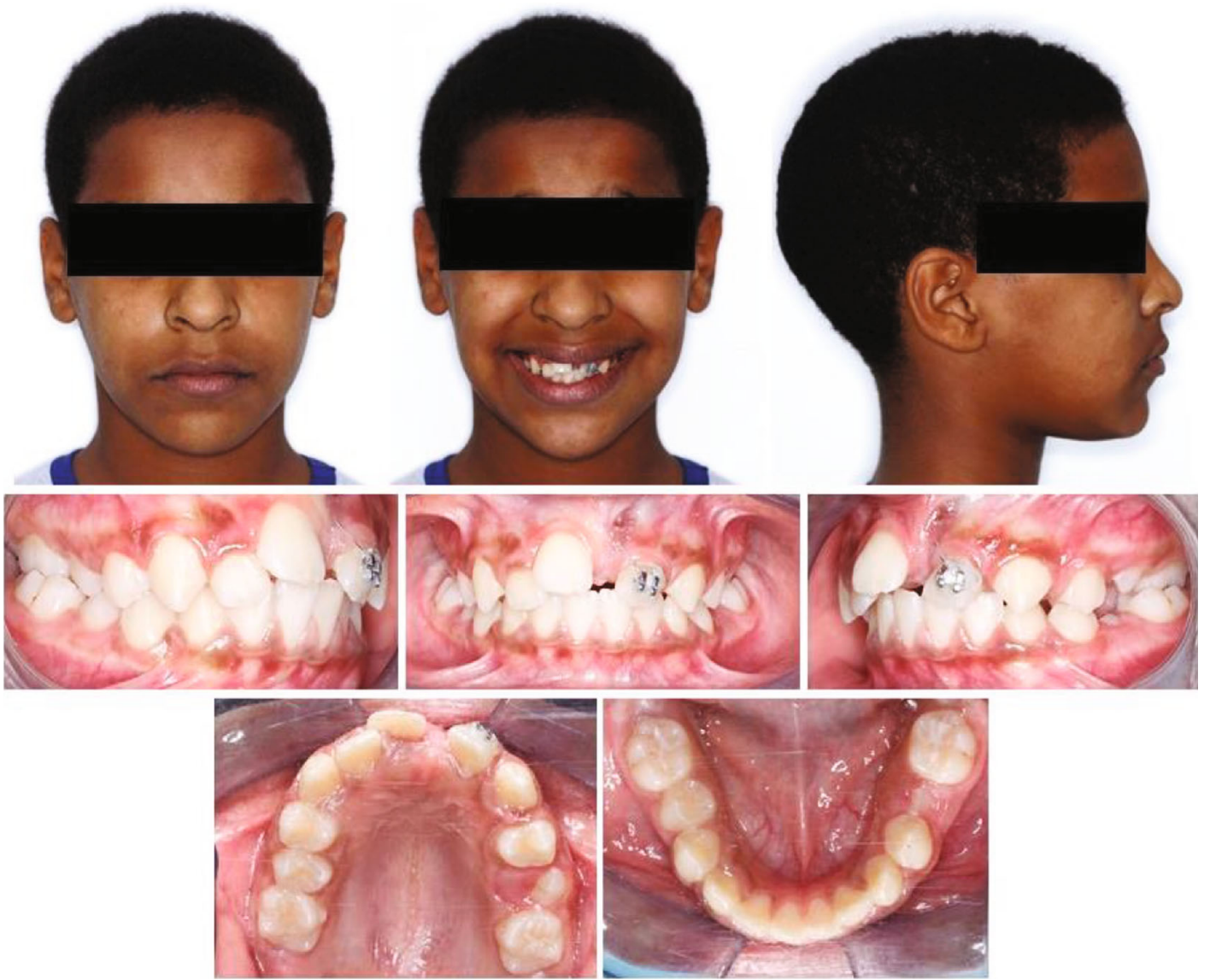

FIgURE 1: Pretreatment extra- and intraoral photographs.

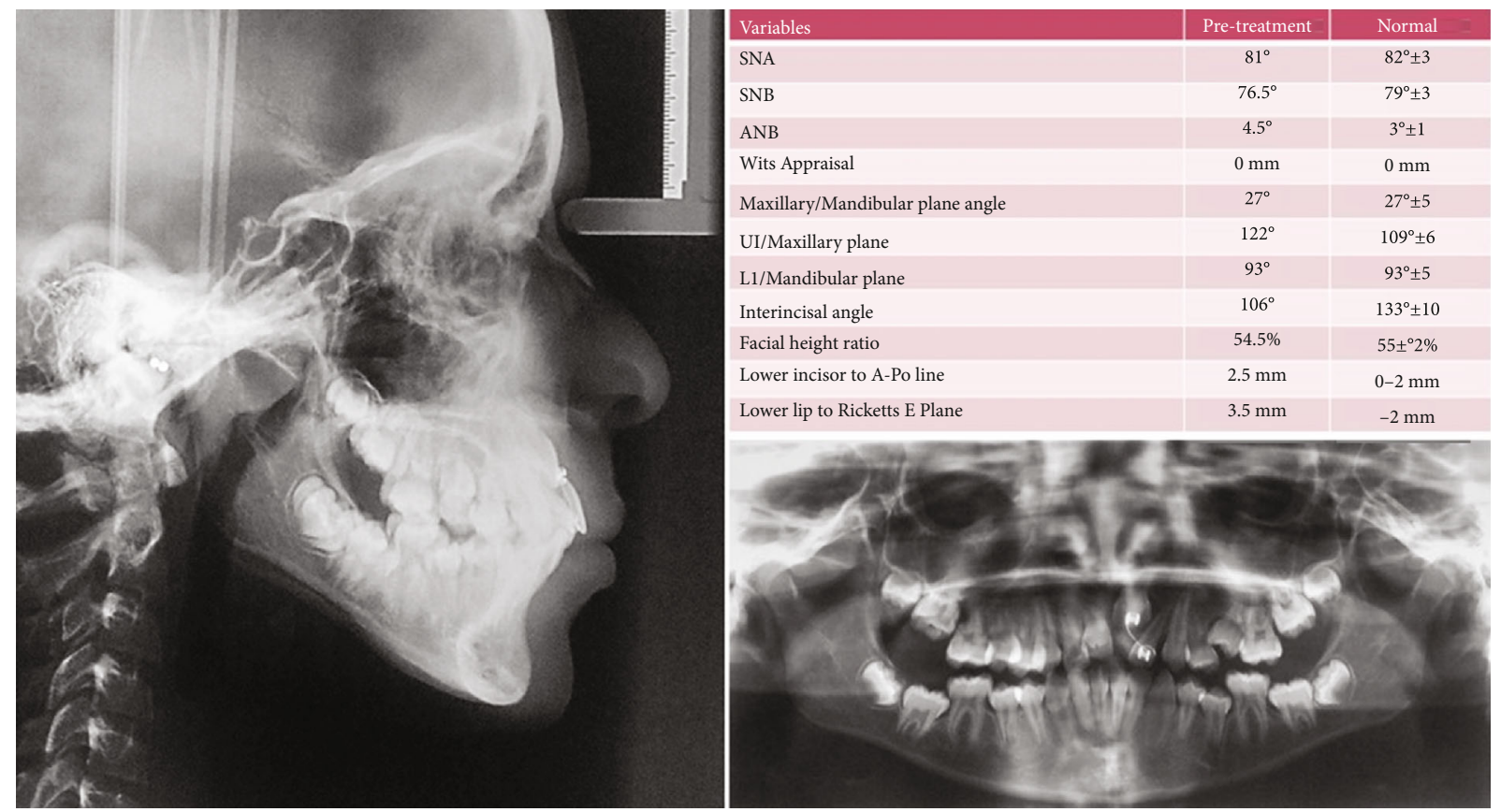

Figure 2: Pretreatment radiographs and analysis. 

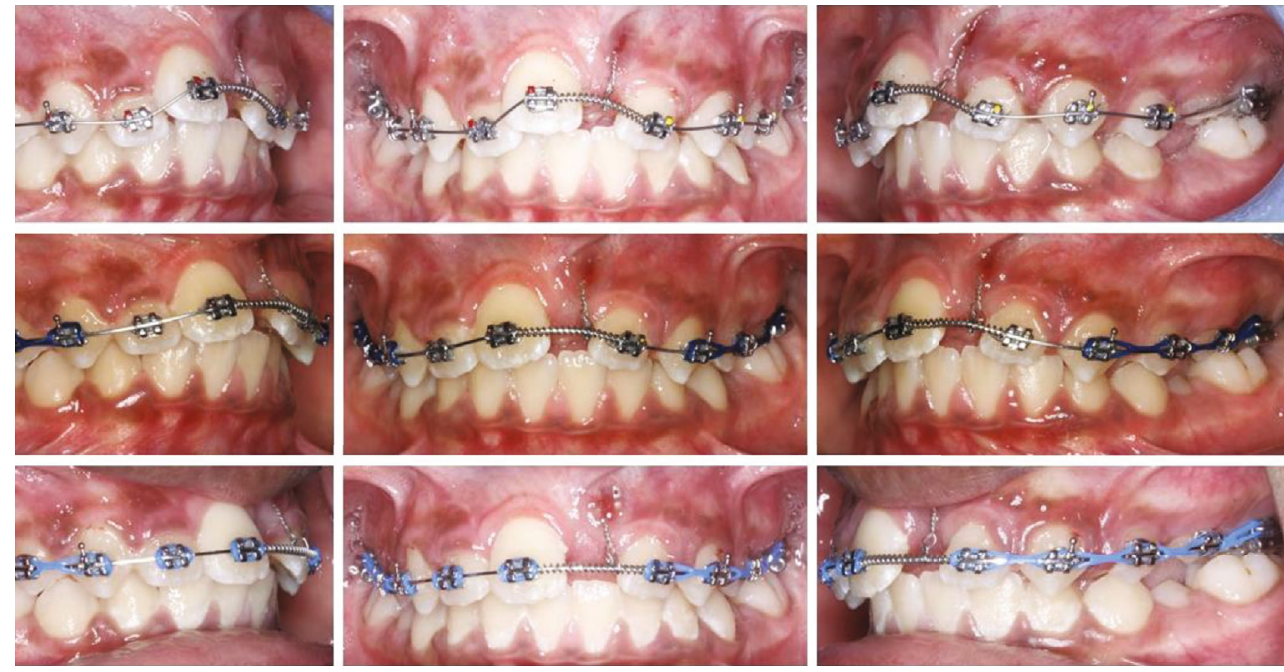

FIGURE 3: Initial stages.
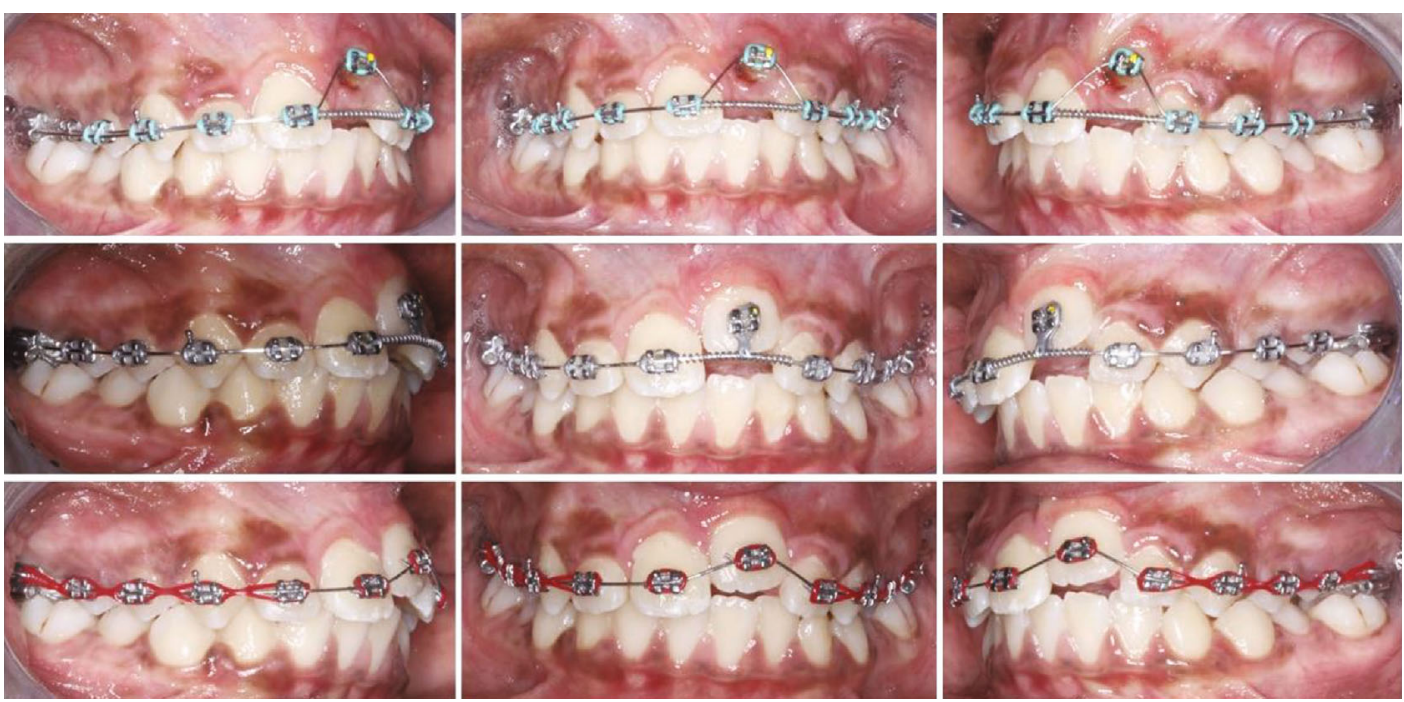

FIgURE 4: Treatment progress.

[14]. The clinical signs of supernumerary teeth are reflected by spacing especially midline diastema, failure of adjacent teeth to erupt mainly upper incisors, and local crowding or irregularity [15].

\section{Case Presentation}

An 11-year, eight-month old Sudanese boy attended to the orthodontic clinic with a chief complaint that "My upper front tooth did not erupt although the dentist attached a wire to pull it with the help of a neighbouring tooth." Medically, he was fit and healthy and had no reported habits. According to his parents, he had a history of a supernumerary tooth in the upper left central incisor, but unfortunately, photos are not available.

2.1. Clinical Examination: Extraoral Features. In the transversal plane, the five-fifths are averagely equal with no facial asymmetry; vertically, the lower facial height is slightly increased, while the sagittal plane shows mild convex facial profile. The soft tissue examination shows average nasolabial angle, competent lips, $90 \%$ of upper incisors on smiling, small buccal corridors, and an average mentolabial fold. The TMJ assessment revealed no clicking, no crepitus, no deviation, or limitation in mouth opening.

2.2. Clinical Examination: Intraoral Features. The patient presented with adequate oral hygiene impacted 21 and mild space discrepancy in both dental arches. The Bolton overall ratio was $89.58 \%$ whereas the anterior ratio was $80.21 \%$. Occlusal assessment exhibited a class II/1 incisor relationship; class II canine relationship; class I molar relationship; increased overjet of $5 \mathrm{~mm}$; reduced overbite; localized crossbite of tooth number 16,15, 25, and 26; and mild shift of the lower centreline to the left (metallic ligature connected between tooth nos. 21 and 22) (Figure 1).

2.3. Radiographic Features. The DPT shows no pathologies or root resorption, presence of all permanent teeth, and an impacted tooth number 21. Analysis of the lateral 


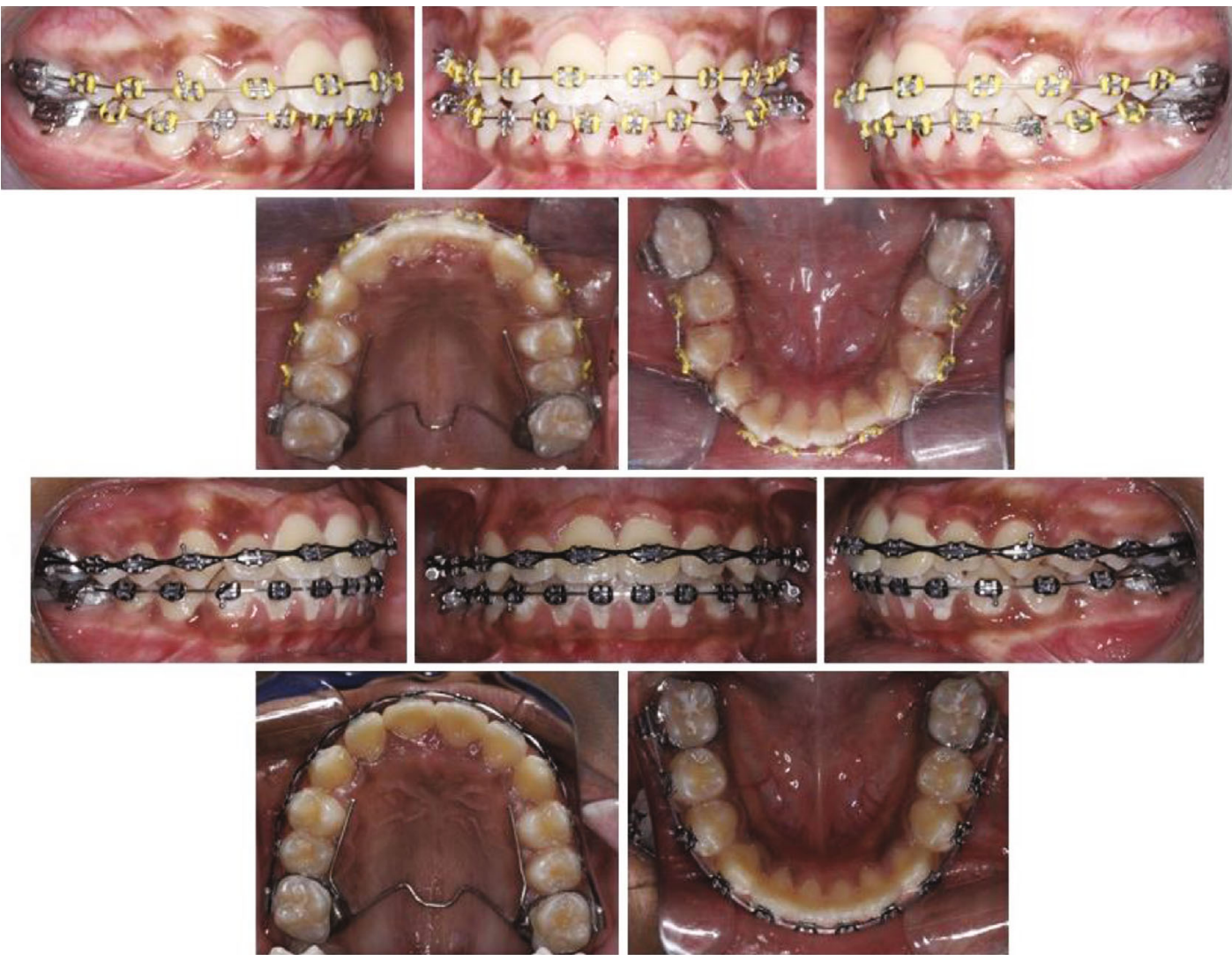

FIgURE 5: Bonding of the lower arch and finishing.

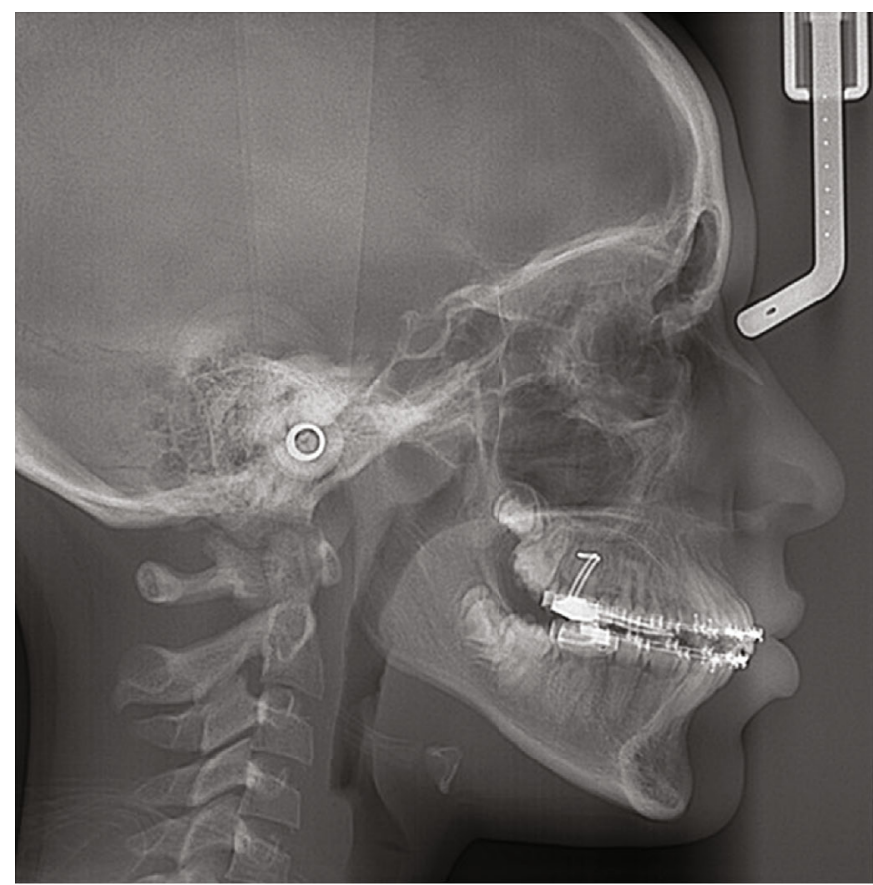

\begin{tabular}{|l|c|c|c|}
\hline Variables & $\begin{array}{l}\text { Pre- } \\
\text { treatment }\end{array}$ & $\begin{array}{l}\text { Mid- } \\
\text { treatment }\end{array}$ & Normal \\
\hline SNA & $81^{\circ}$ & $80.5^{\circ}$ & $82^{\circ} \pm 3$ \\
\hline SNB & $76.5^{\circ}$ & $77^{\circ}$ & $79^{\circ} \pm 3$ \\
\hline ANB & $4.5^{\circ}$ & $3.5^{\circ}$ & $3^{\circ} \pm 1$ \\
\hline Wits Appraisal & $0 \mathrm{~mm}$ & $0 \mathrm{~mm}$ & $0 \mathrm{~mm}$ \\
\hline Maxillary/Mandibular plane angle & $27^{\circ}$ & $30^{\circ}$ & $27^{\circ} \pm 5$ \\
\hline UI/Maxillary plane & $122^{\circ}$ & $124^{\circ}$ & $109^{\circ} \pm 6$ \\
\hline L1/Mandibular plane & $93^{\circ}$ & $101^{\circ}$ & $93^{\circ} \pm 5$ \\
\hline Interincisal angle & $106^{\circ}$ & $104^{\circ}$ & $133^{\circ} \pm 10$ \\
\hline Lower facial height ratio & $24.5^{\circ}$ & $56.5 \%$ & $55 \pm 2 \%$ \\
\hline Lower incisor to A-Po line & $2.5 \mathrm{~mm}$ & $2.5 \mathrm{~mm}$ & $0-2 \mathrm{~mm}$ \\
\hline Lower lip to Ricketts E Plane & $3.5 \mathrm{~mm}$ & $3 \mathrm{~mm}$ & $-2 \mathrm{~mm}$ \\
\hline & & & \\
\hline
\end{tabular}

FIGURE 6: Midtreatment radiographs and analysis.

cephalometric radiograph confirms mild class II skeletal relationship, increased lower anterior facial height, proclined upper incisors relative to the maxillary plane, and convex soft tissue profile (Figure 2).

\section{Treatment Plan}

3.1. Aim of the Treatment. The treatment was aimed at improving the oral hygiene, aligning tooth number 21 into 

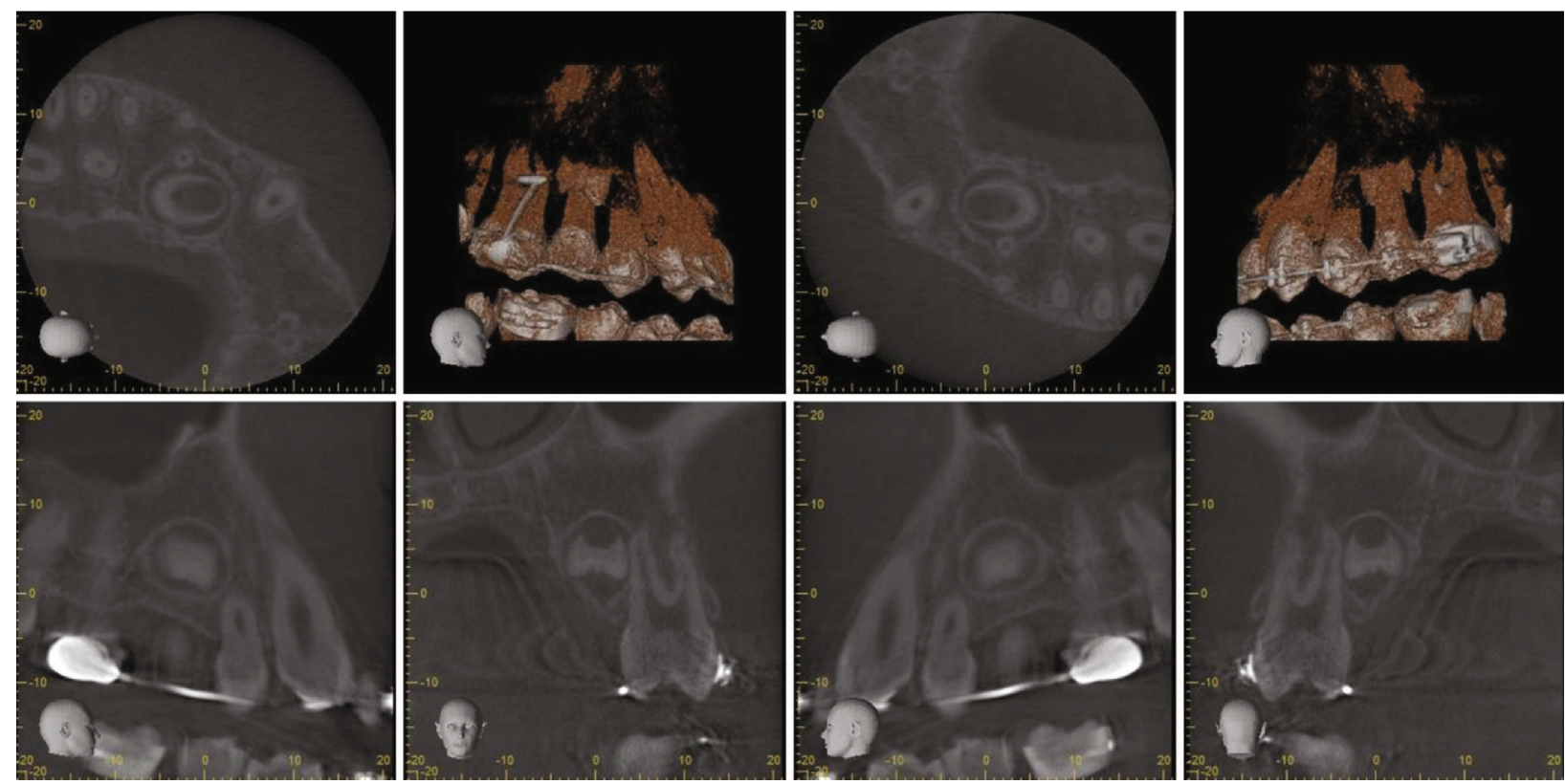

FIGURE 7: CBCT shows new supernumerary tooth developing in the upper left quadrant.

the dental arch, achieving a class I incisor and canine relationships, correcting posterior crossbite, relieving crowding in both dental arches, achieving normal overjet and overbite, improving incisor display on smiling, correcting lower centreline shift, and long-term stability and retention.

3.2. Treatment Strategy. Treatment strategies include improving oral hygiene, comprehensive orthodontic treatment with upper and lower fixed appliance "pre-adjusted edgewise metallic bracket, and Roth prescription with $0.022^{\prime \prime} \times 0.028^{\prime \prime}$ slot"; surgical exposure of tooth number 21 and aligning it using a loop-formed metallic ligature, correcting posterior crossbite employing active TPA with palatal arms; and relieving dental crowding through interdental striping.

\subsection{Treatment Duration. Two years of active treatment.}

3.4. Retention Protocol. The retention protocol comprises of an upper and lower bonded retainer from canine to canine and nighttime vacuum-formed retainer (VFR) for both dental arches.

\section{Treatment Progress}

Initially, TPA is cemented on upper first molars, upper teeth are bonded, and $0.014^{\prime \prime}$ nickel-titanium (Ni-Ti) archwire was placed with a passive coil between 11 and 22 to maintain the space for 21 . The metallic ligature that extended from the impacted tooth is just ligated against the base archwire. In the second visit, the upper archwire changed to $0.016^{\prime \prime} \mathrm{Ni}$ $\mathrm{Ti}$, followed in the next visit by an upper archwire $0.016^{\prime \prime} \times$ $0.022^{\prime \prime} \mathrm{Ni}-\mathrm{Ti}$ and power chain connected the canine to the first molar on each side (Figure 3).

After the alignment of upper teeth, piggyback $0.012^{\prime \prime} \mathrm{Ni}$ Ti archwire was used along with $0.018^{\prime \prime} \times 0.025^{\prime \prime}$ Stainless Steel (SS) base archwire to align tooth number 21 . Once the

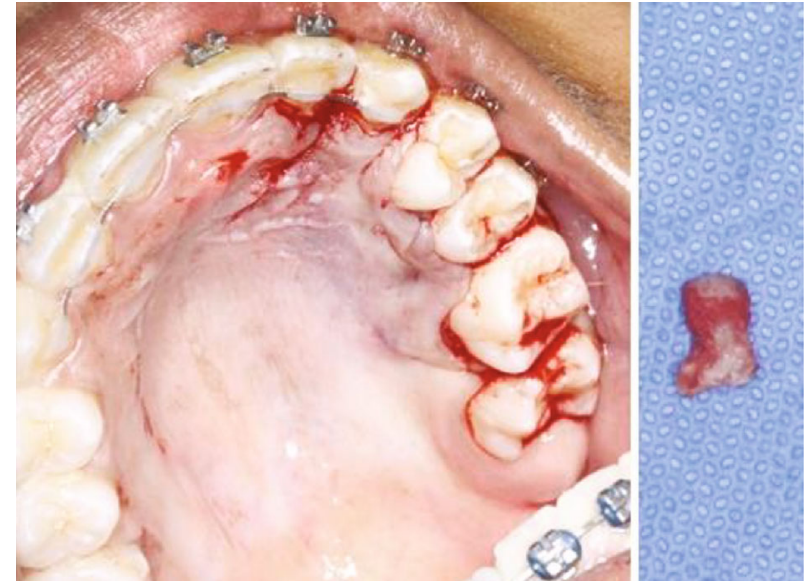

FIGURE 8: Removal of the supernumerary between the teeth 24 and 25.

tooth number 21 approaches the dental arch, the wire mentioned above was replaced by a $0.014^{\prime \prime} \mathrm{Ni}-\mathrm{Ti}$ archwire to achieve full alignment (Figure 4).

In the next visits, treatment started for the lower dental arch, and manual interdental stripping was performed for lower anterior teeth to relieve the crowding.

Meanwhile, the TPA was removed, activated, and recemented to correct the buccal crossbite (Figure 5).

Toward the end of orthodontic treatment, DPT and lateral cephalometric radiographs were taken to evaluate the progress of the treatment.

Radiological examination of the DPT showed the radiopaque area in the upper left premolar area (Figure 6).

The consultation was sought from the oral and maxillofacial radiologist who advised for Cone Beam Computed Tomography (CBCT) for further examination. 

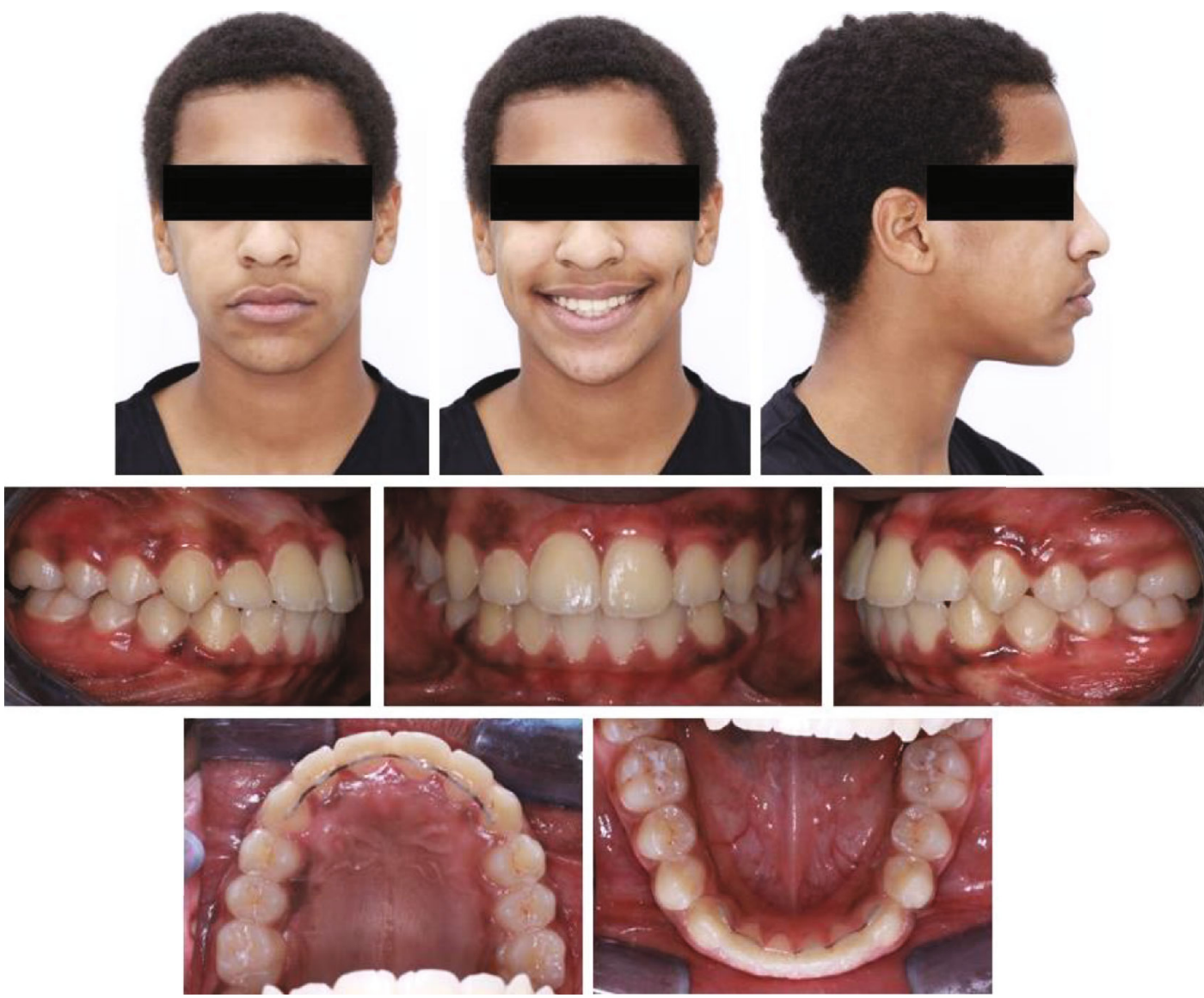

Figure 9: Posttreatment extra- and intraoral photographs.

CBCT revealed the presence of a newly developed supernumerary tooth in the palatal side between the upper left first and second premolars (Figure 7).

The case was discussed with an oral and maxillofacial surgeon who advised for surgical removal of this tooth to eliminate any possibility of future complications.

Patient was transferred to the surgery department for surgical removal of the supernumerary tooth (Figure 8).

The patient followed for two months after the surgery to evaluate the healing process and allow further settling of the occlusion.

After that, both arches were debonded and posttreatment instructions given to the patient (Figure 9).

4.1. Retention Regimen. The retention regimen comprises of fixed upper and lower retainers from canine to canine in addition to upper and lower vacuum-formed retainers (VFRs) for both dental arches. The follow-up will be for 3 years as follows:

(i) $1^{\text {st }}$ year: 4 visits (once every 3 months)-check for oral hygiene and the bonded retainers; the VFRs will be worn at nighttime only

(ii) $2^{\text {nd }}$ year: 2 visits (once every 6 months)-reduce retainer wear (3 nights/week for 6 months, 2 nights/week for the next visit) (iii) $3^{\text {rd }}$ year: 2 visits (once every 6 months) - reduce retainer wear (one night/week for 6 months), check once/week for the next 6 months). Stop the VFRs

\section{Discussion}

The development of supernumerary teeth in the dental arch is not a rare phenomenon, and the incidence, in a decreasing order, is maxillary lateral incisors, mesiodens, maxillary central incisors, and premolars [16]. According to their morphology, supernumerary teeth can be classified into odontomes, rudimentary, tuberculate, and supplemental type [5]. Presence of these teeth in the dental arch might cause many dental problems and complicate orthodontic treatment [16]. One of these dental problems is impaction of the adjacent teeth as it occurred in our case. Early detection and management of extra teeth in the dental arch are a critical factor in minimizing the subsequent dental problems and therefore facilitate orthodontic treatment [17]. The general dental practitioner should learn when to refer the impacted teeth cases to the orthodontist, as these cases require extra tools for diagnosis and more experience in diagnosis and management. One of these tools is $\mathrm{CBCT}$, which provide a precise location for the impacted teeth, determine the accurate position related to adjacent structures, and therefore enable the surgeon for correct surgical removal $[17,18]$. 


\section{Conclusion}

Early detection of impacted supernumerary teeth is essential in achieving good results. General dental practitioners are advised to seek a consultation or refer cases that involve impacted teeth to the orthodontist for better diagnosis and correct management.

In our case, we decided to align the impacted upper left central incisor utilizing a loop-formed metallic ligature and surgical removal of impacted supernumerary tooth in the premolar area to avoid any future complications. Bonded retainers, VFRs, and class I occlusion will provide longterm stability and retention.

\section{Conflicts of Interest}

The authors report no conflicts of interest regarding the publication of this article.

\section{Acknowledgments}

We thank Mohammed Bin Rashid University of Medicine and Health Sciences, the Hamdan Bin Mohammed College of Dental Medicine, Dubai Dental Hospital, as the treatment was performed during the training for the MSc in Orthodontics under the supervision of Dr. Adil Mageet.

\section{References}

[1] A. Chen, J.-K. Huang, S.-J. Cheng, and C.-Y. Sheu, "Nasal teeth: report of three cases," AJNR. American Journal of Neuroradiology, vol. 23, no. 4, pp. 671-673, 2002.

[2] Y. Ingale, A. A. Shankar, S. Routray, M. Agrawal, A. Kadam, and T. Patil, "Ectopic teeth in ovarian teratoma: a rare appearance," Case reports in dentistry, vol. 2013, 3 pages, 2013.

[3] J. D. Niswander and C. Sujaku, "Congenital anomalies of teeth in Japanese children," American Journal of Physical Anthropology, vol. 21, no. 4, pp. 569-574, 1963.

[4] L. D. Rajab and M. A. M. Hamdan, "Supernumerary teeth: review of the literature and a survey of 152 cases," International Journal of Paediatric Dentistry, vol. 12, no. 4, pp. 244254, 2002.

[5] M. T. Garvey, H. J. Barry, and M. Blake, "Supernumerary teeth-an over-view of classification, diagnosis and management," Journal of the Canadian Dental Association, vol. 65, no. 11, pp. 612-616, 1999.

[6] M. N. Mahabob, G. J. Anbuselvan, B. S. Kumar, S. Raja, and S. Kothari, "Prevalence rate of supernumerary teeth among non-syndromic South Indian population: an analysis," Journal of Pharmacy \& Bioallied Sciences, vol. 4, Supplement 2, pp. S373-S375, 2012.

[7] A. H. Brook, "Dental anomalies of number, form, and size: their prevalence in British schoolchildren," Journal of the International Association of Dentistry for Children, vol. 5, no. 2, pp. 37-53, 1974.

[8] P. J. Davis, "Hypodontia and hyperdontia of permanent teeth in Hong Kong schoolchildren," Community Dentistry and Oral Epidemiology, vol. 15, no. 4, pp. 218-220, 1987.

[9] E. C. Küchler, A. G. Costa, M. C. Costa, A. R. Vieira, and J. M. Granjeiro, "Supernumerary teeth vary depending on gender," Brazilian Oral Research, vol. 25, no. 1, pp. 76-79, 2011.
[10] P. V. Rao and M. M. Chidzonga, "Supernumerary teeth: literature review," The Central African Journal of Medicine, vol. 47, no. 1, pp. 22-26, 2001.

[11] A. Shah, D. S. Gill, C. Tredwin, and F. B. Naini, "Diagnosis and management of supernumerary teeth," Dental Update, vol. 35, no. 8, pp. 510-520, 2008.

[12] P. S. Fleming, G. M. Xavier, A. T. DiBiase, and M. T. Cobourne, "Revisiting the supernumerary: the epidemiological and molecular basis of extra teeth," British Dental Journal, vol. 208, no. 1, pp. 25-30, 2010.

[13] L. K. Rubenstein, S. J. Lindauer, R. J. Isaacson, and N. Germane, "Development of supernumerary premolars in an orthodontic population," Oral surgery, oral medicine, oral pathology, vol. 71, no. 3, pp. 392-395, 1991.

[14] G. R. Bayar, K. Ortakoglu, and M. Sencimen, "Multiple impacted teeth: report of 3 cases," European journal of dentistry, vol. 2, no. 1, pp. 73-78, 2008.

[15] J. Seehra, O. Yaqoob, S. Patel et al., "National clinical guidelines for the management of unerupted maxillary incisors in children," British Dental Journal, vol. 224, no. 10, pp. 779785, 2018.

[16] M. A. Scheiner and W. J. Sampson, "Supernumerary teeth: a review of the literature and four case reports," Australian Dental Journal, vol. 42, no. 3, pp. 160-165, 1997.

[17] T. Finkelstein, Y. Shapira, A. M. Pavlidi et al., "Prevalence and characteristics of supernumerary teeth in Israeli orthodontic patients," Journal of Clinical Pediatric Dentistry, vol. 43, no. 4, pp. 244-251, 2019.

[18] R. P. Anthonappa, N. M. King, A. B. M. Rabie, and S. K. Mallineni, "Reliability of panoramic radiographs for identifying supernumerary teeth in children," International journal of paediatric dentistry, vol. 22, no. 1, pp. 37-43, 2012. 